\title{
The evaluation of long-term mechanical properties of wood-based panels by indoor exposure tests
}

\author{
Noboru Sekino ${ }^{1}\left[\right.$ Hideaki Korai $^{2}$
}

Received: 22 December 2017 / Accepted: 25 March 2018 / Published online: 2 May 2018

(c) The Japan Wood Research Society 2018

\begin{abstract}
Wood-based panels such as plywood, oriented strand board, particleboard, and medium-density fiberboard are used for roof, wall and floor sheathing materials in residential construction. However, the service life of these panels is still unknown due to the lack of long-term durability data. In this paper, test results from six different indoor exposure experiments were integrated to investigate the long-term durability of wood-based panels. The indoor exposure tests lasted for a maximum of 10 years, providing the panels with the changes in moisture content that ranged between 5 and $18 \%$. The reduction in mechanical properties was determined to be in the range of $0-16 \%$ for the bending strength, $3-22 \%$ for the modulus of elasticity, $11-31 \%$ for the internal bond strength and $0-8 \%$ for the nail-head pull-through strength. No reduction was recognized for the lateral nail resistance. Furthermore, the concept of deterioration intensity (DI) based on the moisture content history was introduced to predict the long-term durability of the panels, and various calculation methods for DI were discussed so as to increase the correlativity of this property with the reduction in a mechanical property.
\end{abstract}

Keywords Indoor exposure $\cdot$ Mechanical property $\cdot$ Moisture content history $\cdot$ Long-term durability $\cdot$ Wood-based panel

\section{Introduction}

Plywood and oriented strand board (OSB) are widely used for roof, wall and floor sheathing materials in residential construction. Particleboard (PB) and medium-density fiberboard (MDF) are also expected to be put towards such uses, because they help to promote the recycling of wood wastes and the utilization of unused forest resources. In this context, material standards in Japan for MDF and PB have been recently revised and a new category for construction use was introduced $[1,2]$.

While plywood is a veneer-laminated panel with gluelines, OSB, PB, and MDF are the so-called mat-formed panels with glue points (bonding points) between the elements. Mat-formed panels, in general, are less durable than plywood due to the difference in gluing configuration. Therefore, one of the most important properties of these

Noboru Sekino

sekino@iwate-u.ac.jp

1 Faculty of Agriculture, Iwate University, Morioka 020-8550, Japan

2 Forestry and Forest Products Research Institute, Tsukuba 305-8687, Japan panels is long-term durability [3,4]. The durability of matformed panels, in general, is assessed with such accelerated aging tests as the ASTM 6-cycle (American Society for Testing and Materials; ASTM D1037 treatment) [5], APA D-1 and D-4 (American Plywood Association treatments) [6], V313 (European Standard 321 treatment) [7] and Japanese Industrial Standard Wet-bending A or B tests (JIS A5905 and A5908) [1,2]. Most of these tests are composed of a heat-and-water load interlacing with hot-water immersion, boiling, steaming, freezing, drying, and so on. The validity of these tests has been investigated through correlating the deterioration of the panels caused by outdoor exposure tests with that by the accelerated aging tests [8-13].

However, results from the outdoor exposure tests strongly depend on the climatic conditions of the exposure sites [14, 15]. This makes it difficult to predict the deterioration of the panels when they are exposed to the outdoors. To overcome such a disadvantage, the Research Working Group on Wood-based Panels of the Japan Wood Research Society has conducted a durability prediction project since 2004 [16]. The outdoor exposure tests in this project were conducted at eight sites with various climatic conditions in Japan for up to 7 years using several commercial wood-based panels (plywood, OSB, PB and MDF). Thus far, the deterioration 
rates of the mechanical properties at each site have been calculated and their regional differences were discussed [17, 18]. Furthermore, the concept of weathering intensity (WI) as a method of eliminating regional differences has been introduced to standardize a deterioration factor of the woodbased panels exposed to various climate conditions [16-18]. Through the WI, the exposure periods at several sites worldwide that reduce the initial bending strength (MOR) by half were calculated for two types of PBs with different water resistances [16].

Although the results from the outdoor exposure tests enable us to predict the service life of these panels for outdoor use in various places, it is questionable whether the service life can be correlated with that of actual use, such as in roof, wall, and floor sheathings. This is because the mechanisms of panel deterioration differ between outdoor exposure and actual use. The panel surface's deterioration, which is caused by sunlight and penetration of rainwater, is dominant for outdoor exposure tests and biodeterioration adds to this [19]. In actual use, such as in wall sheathings, however, a main deterioration factor is the change in ambient temperature and humidity if an accidental water leakage does not occur. The change in moisture content causes the panels to swell and shrink, which may destroy the bonding points of mat-formed panels [20]. This suggests that long-term follow-up tests for panel mechanical properties are also important to predict the service life of these panels in actual use.

The durability prediction project mentioned above has been conducted not only with outdoor exposure tests but also with indoor exposure tests using the same sample panels. The indoor exposure tests were planned to have the panels experience various changes in moisture content by leaving them in an ordinary room, under the floor, and in an environmental chamber which reproduced the long-term humid condition or cycles of humid-and-dry conditions. Moreover, the test panels were used as materials for roof sheathing and the ceiling of eaves in an experimental house. Test terms of the indoor exposures were up to a maximum of 10 years and the changes in the mechanical properties were investigated. Results from the tests were partly reported by Korai et al. [21] for the exposure to a long-term humid condition or to cycles of humid-and-dry conditions, and by Sekino and Sasaki [22] for the actual use as roof sheathing and the ceiling of eaves. However, an analysis of all of the test results has not been conducted yet.

The first objective of the present study is to investigate panel deterioration through integrating the results from all indoor exposure conditions for the mechanical properties of MOR, modulus of elasticity (MOE), internal bond strength (IB), lateral nail resistance (LNR), and nail-head pull-through resistance (NHPT). The second objective is to investigate the relationships of strength reduction between the indoor exposure and accelerated aging. The third objective is to introduce the concept of deterioration intensity (DI), with the aim of developing a standardized method to predict the long-term durability of wood-based panels. The DI in this research is based on the moisture content history, while the WI mentioned above for outdoor deterioration is based on indirect factors such as precipitation, temperature and relative humidity [16-18].

\section{Experimental}

\section{Sample panels}

In this study, two types of OSB with different raw materials were used, along with two types of PB with different binders, one type of MDF, and plywood as samples. These were among several wood-based panels tested in the project. All panels were commercial products. Table 1 lists the specifications of the sample panels. Both the OSBs [OSB(A) and $\mathrm{OSB}(\mathrm{P})$ ] were class- 3 construction panels as specified by Japanese Agricultural Standards (JAS) [23]. Both the PBs $[\mathrm{PB}(\mathrm{P})$ and $\mathrm{PB}(\mathrm{I})]$ were of a typical three-layer construction with fine particles in the face layer and coarse particles in the core layer, and were 18-P type as specified by JIS A 5908 [2]. Although $\mathrm{PB}(\mathrm{P})$ and $\mathrm{PB}(\mathrm{I})$ are categorized in the same water resistance level of P-type, the actual water resistance somewhat differed judging from the thickness

Table 1 Abbreviations and specifications of the sample panels

\begin{tabular}{llllll}
\hline Abbreviations & Panel type & Binder & $\begin{array}{l}\text { Initial thickness } \\
(\mathrm{mm})\end{array}$ & $\begin{array}{l}\text { Initial density } \\
\left(\mathrm{g} / \mathrm{cm}^{3}\right)\end{array}$ & Raw material \\
\hline OSB(A) & Oriented strand board & PF & 12.1 & 0.63 & Aspen (Populus tremula) \\
OSB(P) & Oriented strand board & PF & 11.5 & 0.67 & Scots pine (Pinus sylvestris) \\
PB(P) & Particleboard & PF & 12.6 & 0.75 & Wood waste \\
PB(I) & Particleboard & MDI & 12.0 & 0.80 & Wood waste \\
MDF(M) & Medium-density fiberboard & MUF & 12.1 & 0.76 & Mixed light hardwoods and wood waste \\
PW(P) & Plywood & PF & 12.0 & 0.60 & Mixed softwoods \\
\hline
\end{tabular}

$P F$ phenol-formaldehyde resin, $M D I$ methylene diphenyl diisocyanate, $M U F$ melamine-urea-formaldehyde resin 
swelling caused by water immersion and residual MOR after boiling, as shown in Table 2. MDF(M) was a 30-M type as specified by JIS A 5905 [1]. PW(P) was 5-ply construction with $\mathrm{CD}$-grade veneers as specified by the construction plywood of JAS [24]. For each type of panel, 30-40 panels with dimensions of $910 \times 1820 \mathrm{~mm}$ were cut into many test pieces measuring $300 \times 300 \mathrm{~mm}$, except for the panels used for roof sheathing and the ceiling of eaves in the experimental house. For each type of panel, many sets of 12 test pieces were prepared so that average density in each set was almost equal, and they were then distributed to undergo initial property tests and indoor exposure tests.

\section{Property tests and initial properties}

Bending tests to determine the MOR and MOE were conducted with test pieces measuring $50 \times 260 \mathrm{~mm}$ in compliance with JIS A 5908 [2]. An IB test was conducted with test pieces measuring $50 \times 50 \mathrm{~mm}$ in compliance with JIS A 5908 [2]. LNR and NHPT tests (both tests combined are hereafter referred to as nail tests) for obtaining basic data for nail-joint performance were conducted with test pieces measuring $50 \times 90$ and $50 \times 50 \mathrm{~mm}$, respectively, in compliance with ASTM D 1037 [25]. The nails used were stainless steel nails (N50; $50 \mathrm{~mm}$ in length, $6.3 \mathrm{~mm}$ in head diameter, $2.8 \mathrm{~mm}$ in shank diameter) and the distance from the edge was $12 \mathrm{~mm}$ in the LNR tests.

Table 2 lists the initial values for the mechanical properties. For OSB and plywood with in-plane anisotropy, the MOR, MOE, and LNR were measured both parallel and perpendicular to their grain. Table 2 also lists the water resistance properties of thickness swelling (TS) after 24-h water immersion and wet-bending strength (Wet-MOR) after 2-h boiling, measured in compliance with JIS A 5908 [2]. Both the OSBs possessed similar mechanical properties, however, $\mathrm{OSB}(\mathrm{P})$ was expected to be more water resistant than $\operatorname{OSB}(\mathrm{A})$ judging from its smaller TS value and its WetMOR retention value being higher than that of $\operatorname{OSB}(A)$. On the other hand, the two PBs possessed fairly different mechanical properties due to differences in panel density (see Table 1) and adhesive; each strength value for PB(I) ranged from 1.4 to 2.6 times that of $\mathrm{PB}(\mathrm{P})$. Judging from the TS and Wet-MOR retention, $\mathrm{PB}(\mathrm{I})$ was expected to be more water resistant than $\mathrm{PB}(\mathrm{P})$.

\section{Exposure conditions}

Six different indoor exposure conditions (No. 1-6 described below) were applied in this research project. Two sets of 12 test pieces measuring $300 \times 300 \mathrm{~mm}$ were subjected to the No. 1-4 conditions without any coating on their cut edges. One set was used for the MOR, MOE, and IB tests, and the other was used for the LNR and NHPT tests. The nails were driven into the test pieces at proper positions prior to exposure.

1. Mild humidity: this condition involved leaving the test pieces in a laboratory at Iwate University, Morioka, Japan. The exposure period was up to a maximum of about 10 years (from October, 2004, to June, 2013) and sample collection was conducted at two separate times. The first one was after about 6 years (August, 2010), and the bending, IB, and nail tests were conducted; the replicate numbers of each test was 8,13 and 12 , respectively. During this exposure (from October, 2004, to August, 2010), the room temperature and relative humidity fluctuated from 20 to $24{ }^{\circ} \mathrm{C}$ and $40-70 \%$ through the year, respectively. After this period, these properties fluctuated from 10 to $27{ }^{\circ} \mathrm{C}$ and $33-60 \%$, respectively. The second sample collection was after 9 years and 8 months, and the IB and nail tests were again conducted (the number of replicates was 12 for each test).

Table 2 Initial mechanical properties and water resistance of the sample panels

\begin{tabular}{|c|c|c|c|c|c|c|c|}
\hline \multirow{3}{*}{ Panels } & \multicolumn{5}{|c|}{ Initial mechanical properties, Mean (Standard deviation), $\mathrm{n}=30$} & \multicolumn{2}{|c|}{ Water resistance } \\
\hline & MOR (MPa) & $\mathrm{MOE}(\mathrm{GPa})$ & \multirow{2}{*}{$\begin{array}{c}\mathrm{IB} \\
(\mathrm{MPa}) \\
\end{array}$} & LNR $(\mathrm{kN})$ & \multirow{2}{*}{$\begin{array}{c}\text { NHPT } \\
(\mathrm{kN}) \\
\end{array}$} & \multirow{2}{*}{$\begin{array}{l}\mathrm{TS} \\
(\%) \\
\end{array}$} & \multirow{2}{*}{$\begin{array}{l}\text { Wet-MOR }(/ /, \mathrm{MPa}) \\
\text { (retention, \%)a }\end{array}$} \\
\hline & $\| \quad \perp$ & $\| \quad \perp$ & & $\| \quad \perp$ & & & \\
\hline OSB(A) & $39.2(6.8), 18.3(3.0)$ & $5.26(0.72), 2.06(0.29)$ & $0.56(0.13)$ & $1.81(0.50), 2.09(0.64)$ & $1.58(0.43)$ & 18.3 & $14.2(36)$ \\
\hline $\operatorname{OsB}(\mathrm{P})$ & $36.8(7.8), 27.4(5.5)$ & $4.97(0.56), 3.25(0.41)$ & $0.64(0.19)$ & $2.08(0.64), 2.00(0.48)$ & $1.69(0.32)$ & 10.4 & $17.7(48)$ \\
\hline $\mathrm{PB}(\mathrm{P})$ & $20.3(2.3)$ & $3.60(0.47)$ & $0.83(0.09)$ & $1.74(0.24)$ & $1.70(0.15)$ & 9.3 & $9.5(47)$ \\
\hline $\mathrm{PB}(\mathrm{I})$ & $28.8(2.1)$ & $4.11(0.22)$ & $2.19(0.18)$ & $2.76(0.23)$ & $2.70(0.27)$ & 6.7 & $14.6(51)$ \\
\hline $\operatorname{MDF}(\mathrm{M})$ & $45.4(2.9)$ & $4.23(0.28)$ & $0.62(0.11)$ & $2.38(0.21)$ & $1.85(0.13)$ & 4.1 & $14.8(33)$ \\
\hline $\mathrm{PW}(\mathrm{P})$ & $68.6(9.7), 35.8(10.8)$ & $7.25(0.85), 2.87(0.56)$ & $1.15(0.31)$ & $2.29(0.33), 2.37(0.28)$ & $2.08(0.25)$ & 5.9 & $28.3(42)$ \\
\hline
\end{tabular}

$O S B, P B, M D F, P W$ see Table $1, / /, \perp$ directions parallel and perpendicular to the grain, respectively

$M O R$ modulus of rupture, $M O E$ modulus of elasticity, $I B$ internal bond strength, $L N R$ lateral nail resistance (N50 nail; edge distance, 12 mm), NHPT nail-head pull-through resistance (N50 nail), TS thickness swelling caused by a 24-h water immersion test $(n=30)$, Wet-MOR wet-bending strength after 2-h boiling specified in JIS A 5908

${ }^{\text {a }}$ Percentage of Wet-MOR to MOR in the initial dry condition 
2. Semi-mild humidity: this condition involved leaving the test pieces under the floor of a model house in Tsukuba, Japan for 5 years (from March, 2005, to March, 2010). During the first year, the temperature and relative humidity under the floor were recorded and the lowest and highest temperatures were $1.3{ }^{\circ} \mathrm{C}$ in the winter and $32.8^{\circ} \mathrm{C}$ in the summer, respectively. The relative humidity was high from March to July and was then reduced from July to September. From January to February and from October to December, the relative humidity was distributed over a wide range (30-90\%). Further details about temperature and humidity conditions are available in Ref [21]. Two test pieces for each panel were collected after 5 years and the bending, IB, and nail tests were conducted; the number of replicates for each test was 8,13 , and 12 , respectively.

3. High humidity: this condition involved exposure to a relative humidity of $90 \%$ and temperature of $20^{\circ} \mathrm{C}$ for 5 years. The test pieces were collected after 1/4-, 1/2-, 1-, 2-, 3-, and 5-year exposures, and the bending, IB, and nail tests were conducted; the number of replicates for each test was 8,13 , and 12, respectively. Further details are available in Ref. [21].

4. Cyclic humidity: this condition involved exposure to a low relative humidity of $45 \%$ and temperature of $20^{\circ} \mathrm{C}$ for 3 months, followed by exposure to a high relative humidity of $90 \%$ and temperature of $20{ }^{\circ} \mathrm{C}$ for 3 months. The process was repeated (one cycle was equal to 6 months) for 10 cycles ( 5 years). The test pieces were collected after 1, 2, 3, 4, 6, and 10 cycles, and the bending, IB, and nail tests were conducted; the number of replicates was 8,13 , and 12 for each test, respectively. Further details are available in Ref [21].

5. Roof sheathing: details are shown in the next "Ceiling of eaves".

6. Ceiling of eaves: sample panels, measured $910 \times 1820$ and $455 \times 910 \mathrm{~mm}$, were used for roof sheathing and the ceiling of eaves, respectively, in the experimental house that was built in Morioka, Japan, on December, 2003. After an actual service of 9 years and 6 months from December, 2003 to June, 2013, the sample panels were taken out and the bending, IB, and nail tests were conducted; the number of replicates for each test was 20-40, 24-60, and 6-25, respectively. During the last year (from December, 2012 to November, 2013), the temperature and relative humidity in attic space and under the eave were recorded. In the attic, the lowest and highest monthly average temperatures were $-1{ }^{\circ} \mathrm{C}$ in February and $30{ }^{\circ} \mathrm{C}$ in August, respectively, and the monthly average relative humidity fluctuated from 42 to $62 \%$. Likewise, the lowest and highest monthly average temperatures under the eave were $-3{ }^{\circ} \mathrm{C}$ in February and $26^{\circ} \mathrm{C}$ in August, respectively, and the monthly aver- age relative humidity fluctuated from 66 to $87 \%$. Further details about the experimental house and temperature and humidity conditions are available in Ref. [22].

All samples collected after each exposure were fully reconditioned at $20{ }^{\circ} \mathrm{C}$ and a relative humidity of $60 \%$ for more than 2 weeks, and then tested for their mechanical properties. Regarding the bending tests used for the OSB and plywood panels, the direction of the span was parallel to the surface grain for the exposure conditions No. 1-4, whereas it was perpendicular to the surface grain for No. 5 and 6. Likewise, the loading direction in the LNR test was parallel to the surface grain for the exposure conditions No. $1-4$, whereas it was basically perpendicular to the surface grain for No. 5 and 6 (the parallel direction accounted for less than $10 \%$ of the total).

\section{Results}

\section{Moisture content history}

The changes in the moisture content of sample panels during the exposure terms are substantial and represent crucial data when the deterioration of the mechanical properties of the panels is discussed. Unfortunately, however, direct monitoring of the moisture content of the sample panels had not been conducted in this research project. Instead, the changes in ambient temperature and humidity were recorded. Therefore, changes in the moisture content during the exposure (moisture content history) were predicted by the use of sorption isotherms obtained for wood-based panels similar to those used in this project [26].

The prediction results are summarized in Table 3, in which the lowest and highest moisture contents $\left(\mathrm{MC}_{\mathrm{L}}\right.$, $\mathrm{MC}_{\mathrm{H}}$ ) are listed. These values mainly correspond to the lowest and highest relative humidity conditions during the exposures, respectively. Table 3 also lists the difference $(\triangle \mathrm{MC})$ in the moisture contents between $\mathrm{MC}_{\mathrm{L}}$ and $\mathrm{MC}_{\mathrm{H}}$. Focusing on the average value of $\mathrm{MC}_{\mathrm{H}}$ for each exposure, it was ordered as follows: 'Mild humidity' (11.2\%) and 'Roof sheathing' $(11.2 \%)<$ 'Semi-mild humidity' $(12.9 \%)<$ 'High humidity' (15.1\%) and 'Cyclic humidity' (15.1\%)< ‘Ceiling of the eave' (16.1\%). Although 'Mild humidity' and 'Roof sheathing' showed the same $\mathrm{MC}_{\mathrm{H}}$, the $\triangle \mathrm{MC}$ differed between them: 'Roof sheathing' showed a greater $\triangle \mathrm{MC}$ than 'Mild humidity' because of its lower $\mathrm{MC}_{\mathrm{L}}$. The moisture content history over all exposure conditions ranged between 5 and $18 \%$.

There would be a variety in the moisture content history for in-service wood-based panels. Sekino et al. [26] reported that the moisture contents of wood-based panels ranged from 3 to $18 \%$ when they were subjected to extreme 
Table 3 Moisture content (MC, \%) history of sample panels under each indoor exposure test

\begin{tabular}{|c|c|c|c|c|c|c|c|c|c|c|c|c|c|c|c|c|}
\hline \multirow[t]{2}{*}{ Panels } & \multicolumn{3}{|c|}{ Mild humidity } & \multicolumn{3}{|c|}{ Semi-mild humidity } & \multirow{2}{*}{$\begin{array}{l}\text { High humidity } \\
\text { MC }\end{array}$} & \multicolumn{3}{|c|}{ Cyclic humidity } & \multicolumn{3}{|c|}{ Roof sheathing } & \multicolumn{3}{|c|}{ Ceiling of eave } \\
\hline & $\mathrm{MC}_{\mathrm{L}}$ & $\mathrm{MC}_{\mathrm{H}}$ & $\Delta \mathrm{MC}$ & $\mathrm{MC}_{\mathrm{L}}$ & $\mathrm{MC}_{\mathrm{H}}$ & $\Delta \mathrm{MC}$ & & $\mathrm{MC}_{\mathrm{L}}$ & $\mathrm{MC}_{\mathrm{H}}$ & $\Delta \mathrm{MC}$ & $\mathrm{MC}_{\mathrm{L}}$ & $\mathrm{MC}_{\mathrm{H}}$ & $\Delta \mathrm{MC}$ & $\mathrm{MC}_{\mathrm{L}}$ & $\mathrm{MC}_{\mathrm{H}}$ & $\Delta \mathrm{MC}$ \\
\hline $\mathrm{OSB}(\mathrm{A})$ & 6.7 & 11.2 & 4.5 & 7.7 & 12.1 & 4.4 & 16.2 & 7.5 & 16.2 & 8.7 & 5.3 & 11.2 & 5.9 & 9.1 & 17.6 & 8.5 \\
\hline $\mathrm{OSB}(\mathrm{P})$ & 6.7 & 11.2 & 4.5 & 7.7 & 12.1 & 4.4 & 16.2 & 7.5 & 16.2 & 8.7 & 5.3 & 11.2 & 5.9 & 9.1 & 17.6 & 8.7 \\
\hline $\mathrm{PB}(\mathrm{P})$ & 8.5 & 12.3 & 3.8 & 8.8 & 15.5 & 6.7 & 15.2 & 9.0 & 15.2 & 6.2 & 7.3 & 12.3 & 5.0 & 9.0 & 15.2 & 6.2 \\
\hline $\mathrm{PB}(\mathrm{I})$ & 7.7 & 11.1 & 3.4 & 7.9 & 14.0 & 6.1 & 13.7 & 8.1 & 13.7 & 5.6 & 6.6 & 11.1 & 4.5 & 8.1 & 13.7 & 5.6 \\
\hline $\operatorname{MDF}(\mathrm{M})$ & 7.6 & 10.0 & 2.4 & 8.5 & 10.9 & 2.4 & 13.3 & 8.2 & 13.3 & 5.1 & 6.1 & 10.1 & 4.0 & 8.2 & 13.3 & 5.1 \\
\hline $\mathrm{PW}(\mathrm{P})$ & 10.1 & 11.5 & 1.4 & 9.1 & 13.0 & 3.9 & 16.2 & 8.8 & 16.2 & 7.4 & 6.1 & 12.0 & 5.9 & 8.8 & 16.2 & 7.4 \\
\hline Average & 7.9 & 11.2 & 3.3 & 8.3 & 12.9 & 4.7 & 15.1 & 8.2 & 15.1 & 7.0 & 6.1 & 11.2 & 5.2 & 9.9 & 16.5 & 6.6 \\
\hline
\end{tabular}

$O S B, P B, M D F, P W$ see Table $1, M C_{L}$ lowest moisture content (\%), $M C_{H}$ highest moisture content (\%), $\Delta M C$ the difference between the lowest and the highest MC

temperature-humidity fluctuation from $40{ }^{\circ} \mathrm{C}$ and $10 \%$ to $10{ }^{\circ} \mathrm{C}$ and $95 \%$, respectively, which was thought to be the largest fluctuation present in actual uses such as in roof, wall, and floor sheathings in Japan. This predicted change in moisture content is close to that experienced over all of the exposure conditions in the present study (5-18\%), which suggests that the moisture content history involved in this exposure research project covers the range of actual annual changes in moisture content in Japan. It can be also confirmed that the moisture content history is far from a moisture condition that may cause wood decay. Because wood fungi need free water in wood which appears in moisture contents more than a fiber saturation point.

\section{Integration of test results}

Retentions of the mechanical properties of the sample panels subjected to six different exposure conditions are found in Table 4, where the retentions are defined by a percentage of the average value demonstrated after exposure in comparison to the initial value (retentions which exceed $100 \%$ were denoted as $100 \%$ ). To make it easier to see a trend in the reductions in mechanical properties, retention values less than three quarters of the initial values are highlighted in italic bold. Results displaying such larger reductions were limited to particular panels, properties, and exposure conditions. For example, LNR tests tended to have a higher retention than other properties, irrespective of the panel type and exposure conditions. On the other hand, the reduction in IB and MOE was prominent for $\operatorname{OSB}(\mathrm{A})$.

The reductions in the mechanical properties shown in Table 4 were essentially derived from the moisture content history shown in Table 3. However, it is not easy to directly connect these values since there are many factors to consider. For example, the space distribution of moisture in a panel affects an individual mechanical property in a different way, and the speed of change of moisture content affects the stress generation at the interface between the wood element and adhesive. In addition to these factors, the uncertainty in the initial values of the individual test sample affects the changes in retention since each sample set was prepared only on the basis of equality of average panel density.

Therefore, first, data from all exposures were integrated and a distribution (histogram) of the mechanical properties for each panel was produced. Figure 1, for example, shows the histograms for the IB test, with treatment values being compared to those before exposure (initial data). The panels except $\mathrm{MDF}(\mathrm{M})$ and $\mathrm{PW}(\mathrm{P})$ showed a statistical significant reduction in the mean value of IB in the range of $11-31 \%$, dependent on the panel type. This trial roughly demonstrates whether the sample panels maintain their initial performance after they have experienced various moisture changes via being used as roof, wall, or floor sheathings in Japan up to a maximum of 10 years.

The results for the other mechanical properties are listed in Table 5. The reductions in MOR and MOE were in the range of $0-16$ and $3-22 \%$, respectively. The reduction in the IB tended to be greater than that of bending properties. On the other hand, there was no reduction in the LNR for all tested panels. In the NHPT, there was a slight reduction of less than $8 \%$ for some of the panels. Little to no reduction in nail-joint performance was recognized here, and this finding can be one of the evidences that the seismic resistance of wooden buildings sheathed with wood-based panels does not deteriorate easily, unless the panels experience extreme moisture conditions resulting wood decay. Furthermore, the dominance in mechanical durability among the sample panels was in the order $\mathrm{MDF}(\mathrm{M}) \simeq \mathrm{PW}(\mathrm{P}) \simeq \mathrm{PB}(\mathrm{I})>\mathrm{OSB}$ $(\mathrm{P})>\mathrm{PB}(\mathrm{P})>\mathrm{OSB}(\mathrm{A})$ as judged by the reductions in overall mechanical properties shown in Table 5. It should be noted that the order shown here probably depends on the level and duration of moisture content, or in other words, on the quality and quantity of the moisture content history. This implies that the order shown here may have somewhat changed if other samples collected at different times had been included. 
Table 4 Retentions of mechanical properties for panels subjected to six different exposure conditions

\begin{tabular}{|c|c|c|c|c|c|c|c|c|c|c|c|c|c|c|c|c|c|}
\hline \multirow[t]{2}{*}{ Panels } & \multicolumn{2}{|c|}{ Mild humidity } & \multirow{2}{*}{$\begin{array}{l}\text { Semi- } \\
\text { mild } \\
\text { humidity } \\
5-y\end{array}$} & \multicolumn{6}{|c|}{ High humidity } & \multicolumn{6}{|c|}{ Cyclic humidity } & \multirow{2}{*}{$\begin{array}{l}\text { Roof } \\
\text { sheath- } \\
\text { ing } \\
9.5-y\end{array}$} & \multirow{2}{*}{$\begin{array}{l}\text { Ceiling } \\
\text { of eave } \\
9.5-y\end{array}$} \\
\hline & $6-\mathrm{y}$ & $10-y$ & & $1 / 4-y$ & $1 / 2-\mathrm{y}$ & $1-\mathrm{y}$ & $2-\mathrm{y}$ & $3-y$ & $5-\mathrm{y}$ & $1 / 2-\mathrm{y}$ & $1-\mathrm{y}$ & $3 / 2-y$ & $2-y$ & $3-\mathrm{y}$ & $5-\mathrm{y}$ & & \\
\hline \multicolumn{18}{|c|}{ Retention of bending strength, MOR (\%) } \\
\hline $\operatorname{OSB}(\mathrm{A})$ & 87 & - & $71^{\mathrm{a}}$ & 75 & 83 & 75 & 76 & 76 & 74 & 81 & 70 & 76 & 74 & 79 & 64 & 100 & 84 \\
\hline $\operatorname{OSB}(\mathrm{P})$ & 91 & - & 95 & 91 & 100 & 86 & 98 & 83 & 81 & 90 & 77 & 97 & 94 & 96 & 92 & 98 & 97 \\
\hline $\mathrm{PB}(\mathrm{P})$ & 96 & - & 96 & 83 & 100 & 100 & 87 & 72 & 67 & 90 & 85 & 98 & 86 & 88 & 75 & 100 & 100 \\
\hline $\mathrm{PB}(\mathrm{I})$ & 100 & - & 100 & 100 & 99 & 99 & 96 & 92 & 85 & 100 & 100 & 99 & 94 & 100 & 95 & 100 & 100 \\
\hline $\operatorname{MDF}(\mathrm{M})$ & 100 & - & 100 & 94 & 94 & 95 & 95 & 89 & 79 & 89 & 95 & 98 & 92 & 92 & 87 & 100 & 100 \\
\hline $\mathrm{PW}(\mathrm{P})$ & 75 & - & 75 & 80 & 78 & 79 & 88 & 75 & 80 & 65 & 68 & 100 & 80 & 80 & 88 & 100 & 100 \\
\hline \multicolumn{18}{|c|}{ Retention of modulus of elasticity, MOE (\%) } \\
\hline $\mathrm{OSB}(\mathrm{A})$ & 83 & - & 69 & 79 & 83 & 64 & 75 & 62 & 62 & 76 & 67 & 77 & 69 & 63 & 56 & 96 & 77 \\
\hline $\operatorname{OSB}(\mathrm{P})$ & 85 & - & 91 & 86 & 94 & 79 & 88 & 76 & 73 & 88 & 78 & 93 & 84 & 84 & 74 & 100 & 99 \\
\hline $\mathrm{PB}(\mathrm{P})$ & 91 & - & 90 & 85 & 94 & 97 & 80 & 67 & 66 & 90 & 84 & 95 & 81 & 80 & 72 & 100 & 100 \\
\hline $\mathrm{PB}(\mathrm{I})$ & 100 & - & 94 & 100 & 98 & 96 & 92 & 84 & 75 & 100 & 96 & 100 & 89 & 87 & 90 & 100 & 98 \\
\hline $\operatorname{MDF}(\mathrm{M})$ & 100 & - & 99 & 95 & 94 & 93 & 96 & 85 & 75 & 92 & 92 & 96 & 91 & 85 & 84 & 100 & 100 \\
\hline $\mathrm{PW}(\mathrm{P})$ & 85 & - & 85 & 87 & 80 & 97 & 91 & 80 & 89 & 93 & 85 & 100 & 88 & 78 & 85 & 100 & 86 \\
\hline \multicolumn{18}{|c|}{ Retention of internal bond strength, IB (\%) } \\
\hline $\mathrm{OSB}(\mathrm{A})$ & 61 & 71 & 64 & 68 & 66 & 65 & 70 & 67 & 69 & 62 & 56 & 63 & 55 & 75 & 33 & 86 & 76 \\
\hline $\mathrm{OSB}(\mathrm{P})$ & 83 & 90 & 92 & 88 & 94 & 82 & 93 & 68 & 82 & 100 & 80 & 77 & 75 & 86 & 72 & 88 & 89 \\
\hline $\mathrm{PB}(\mathrm{P})$ & 87 & 78 & 90 & 84 & 92 & 83 & 78 & 52 & 83 & 88 & 75 & 79 & 79 & 90 & 69 & 75 & 80 \\
\hline $\mathrm{PB}(\mathrm{I})$ & 89 & 86 & 93 & 100 & 95 & 90 & 89 & 85 & 85 & 100 & 100 & 99 & 89 & 93 & 87 & 84 & 88 \\
\hline $\operatorname{MDF}(\mathrm{M})$ & 100 & 100 & 100 & 100 & 100 & 77 & 100 & 100 & 97 & 100 & 100 & 100 & 95 & 100 & 100 & 88 & 100 \\
\hline $\mathrm{PW}(\mathrm{P})$ & 93 & 98 & 100 & 79 & 94 & 100 & 100 & 76 & 100 & 100 & 90 & 100 & 84 & 89 & 74 & 77 & 100 \\
\hline \multicolumn{18}{|c|}{ Retention of internal lateral nail resistance, LNR (\%) } \\
\hline $\mathrm{OSB}(\mathrm{A})$ & 100 & 94 & 87 & 87 & 87 & 99 & 100 & 100 & 93 & 100 & 100 & 89 & 100 & 100 & 92 & 85 & 88 \\
\hline $\operatorname{OSB}(\mathrm{P})$ & 88 & 98 & 100 & 99 & 100 & 100 & 100 & 100 & 100 & 100 & 100 & 91 & 79 & 100 & 100 & 100 & 100 \\
\hline $\mathrm{PB}(\mathrm{P})$ & 94 & 88 & 100 & 100 & 100 & 99 & 96 & 100 & 100 & 100 & 100 & 98 & 100 & 100 & 99 & 76 & 99 \\
\hline $\mathrm{PB}(\mathrm{I})$ & 100 & 100 & 100 & 100 & 100 & 100 & 100 & 100 & 99 & 100 & 100 & 100 & 100 & 100 & 100 & 100 & 100 \\
\hline $\operatorname{MDF}(\mathrm{M})$ & 100 & 100 & 100 & 100 & 100 & 100 & 100 & 100 & 99 & 99 & 100 & 99 & 98 & 100 & 99 & 100 & 98 \\
\hline $\mathrm{PW}(\mathrm{P})$ & 100 & 100 & 100 & 99 & 100 & 100 & 100 & 100 & 98 & 98 & 90 & 97 & 100 & 100 & 100 & 95 & 94 \\
\hline \multicolumn{18}{|c|}{ Retention of nail-head pull-through resistance, NHPT (\%) } \\
\hline $\operatorname{OSB}(\mathrm{A})$ & 99 & 97 & 100 & 75 & 77 & 100 & 100 & 89 & 100 & 90 & 81 & 95 & 94 & 96 & 93 & 80 & 81 \\
\hline $\operatorname{OSB}(\mathrm{P})$ & 100 & 95 & 95 & 94 & 97 & 100 & 86 & 95 & 100 & 100 & 100 & 100 & 96 & 100 & 100 & 74 & 88 \\
\hline $\mathrm{PB}(\mathrm{P})$ & 100 & 94 & 95 & 94 & 96 & 94 & 88 & 95 & 91 & 72 & 94 & 96 & 98 & 93 & 91 & 84 & 84 \\
\hline $\mathrm{PB}(\mathrm{I})$ & 100 & 95 & 100 & 90 & 96 & 99 & 93 & 98 & 92 & 72 & 93 & 96 & 91 & 100 & 96 & 83 & 86 \\
\hline $\operatorname{MDF}(\mathrm{M})$ & 98 & 100 & 99 & 96 & 95 & 99 & 100 & 95 & 99 & 77 & 99 & 99 & 99 & 100 & 99 & 76 & 90 \\
\hline $\mathrm{PW}(\mathrm{P})$ & 100 & 100 & 100 & 93 & 100 & 100 & 100 & 88 & 100 & 96 & 95 & 100 & 100 & 100 & 100 & 94 & 97 \\
\hline
\end{tabular}

$O S B, P B, M D F, P W$ see Table 1

a'Retentions less than three quarters of the initial values are shown in italic bold, '-y' shows '-year'

\section{Comparison of strength reduction between indoor exposure and accelerated aging}

Various accelerated aging tests such as ASTM 6-cycle [5], V313 [7] and JIS Wet-bending A or B tests [1] have been conducted for the sample panels from this study to investigate correlations of panel deterioration between outdoor exposure and accelerated aging conditions [27-29].
However, correlations between indoor exposure and accelerated aging have not yet been investigated. As a first trial for such an investigation, the strength reductions shown in Table 5 were compared with those caused by JIS Wetbending B treatment, namely, 2-h boiling. To eliminate the negative effect of moisture on the strength of the panels, the test samples after 2-h of boiling were fully reconditioned to air-dry conditions (hereafter, this is referred to as JIS BD), 

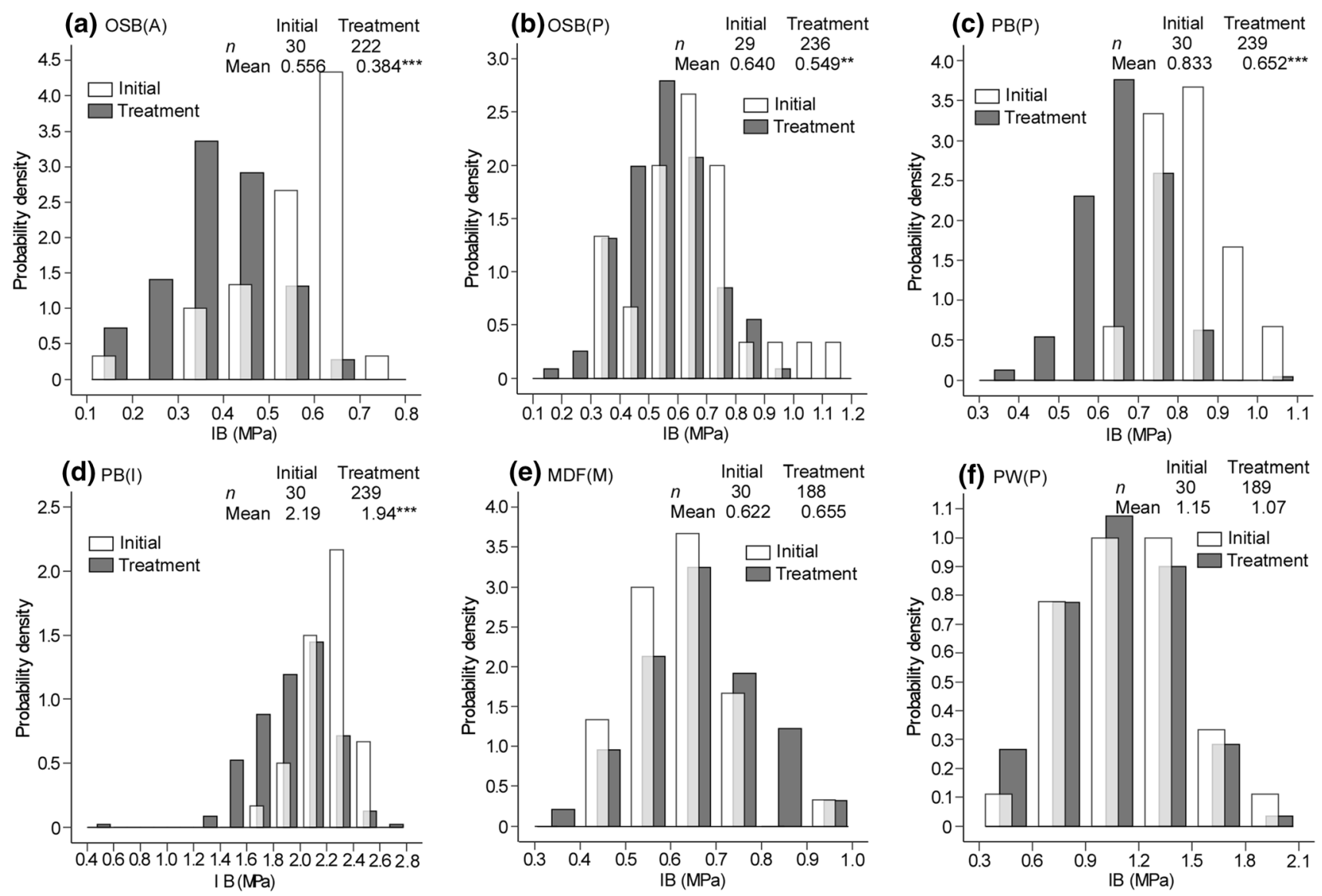

Fig. 1 Comparison of IB histograms before and after indoor exposure treatment. $* *$ and $* * *$ indicate significant difference at 1 and $0.1 \%$ levels, respectively

Table 5 Reduction percentage in the mean value of mechanical properties after indoor exposures

\begin{tabular}{llclll}
\hline Panels & MOR & MOE & IB & LNR & NHPT \\
\hline OSB(A) & $16^{* * *}$ & $22^{* * *}$ & $31^{* * *}$ & - & - \\
OSB(P) & $6^{*}$ & $10^{* *}$ & $14^{* *}$ & - & - \\
PB(P) & $8^{* *}$ & $10^{* * *}$ & $22 * * *$ & - & $8^{* * *}$ \\
PB(I) & - & $3^{*}$ & $11^{* * *}$ & - & $6^{* *}$ \\
$\operatorname{MDF}(\mathrm{M})$ & $5^{* *}$ & $6^{* *}$ & - & - & $4 *$ \\
$\operatorname{PW}(\mathrm{P})$ & $13^{* * *}$ & $8^{* *}$ & - & - & - \\
\hline
\end{tabular}

$O S B, P B, M D F, P W$ see Table 1

MOR, MOE, IB, LNR, NHPT see Table 2

$*$, **, and $* * *$ indicate significant difference at 5,1 and $0.1 \%$ levels, respectively

- indicates no significant difference

and were then tested to determine their mechanical properties. Figure 2 compares the strength reductions between the results of the indoor exposure (Table 5) and JIS BD. Note that the two additional broken lines represent a half and a quarter of the reduction caused by JIS BD. It was found that strength reductions caused by the indoor exposure up to a maximum of 10 years were less than a half of those caused by JIS $\mathrm{BD}$, and less than a quarter when it comes to MOR and nail-joint performances.

\section{Discussion}

\section{Introduction of DI}

In the "Results" section, the relationships between the moisture content history and reduction in mechanical properties were not discussed because it is not clear how a DI based on the moisture content histories should be incorporated. In this "Discussion" section, the concept of DI is introduced and a calculation method for DI which correlates best with the reduction in mechanical properties is discussed to develop a standardized method to predict the long-term durability of the panels.

Excluding biodegradation, a main factor that deteriorates the mechanical properties of wood-based panels is 

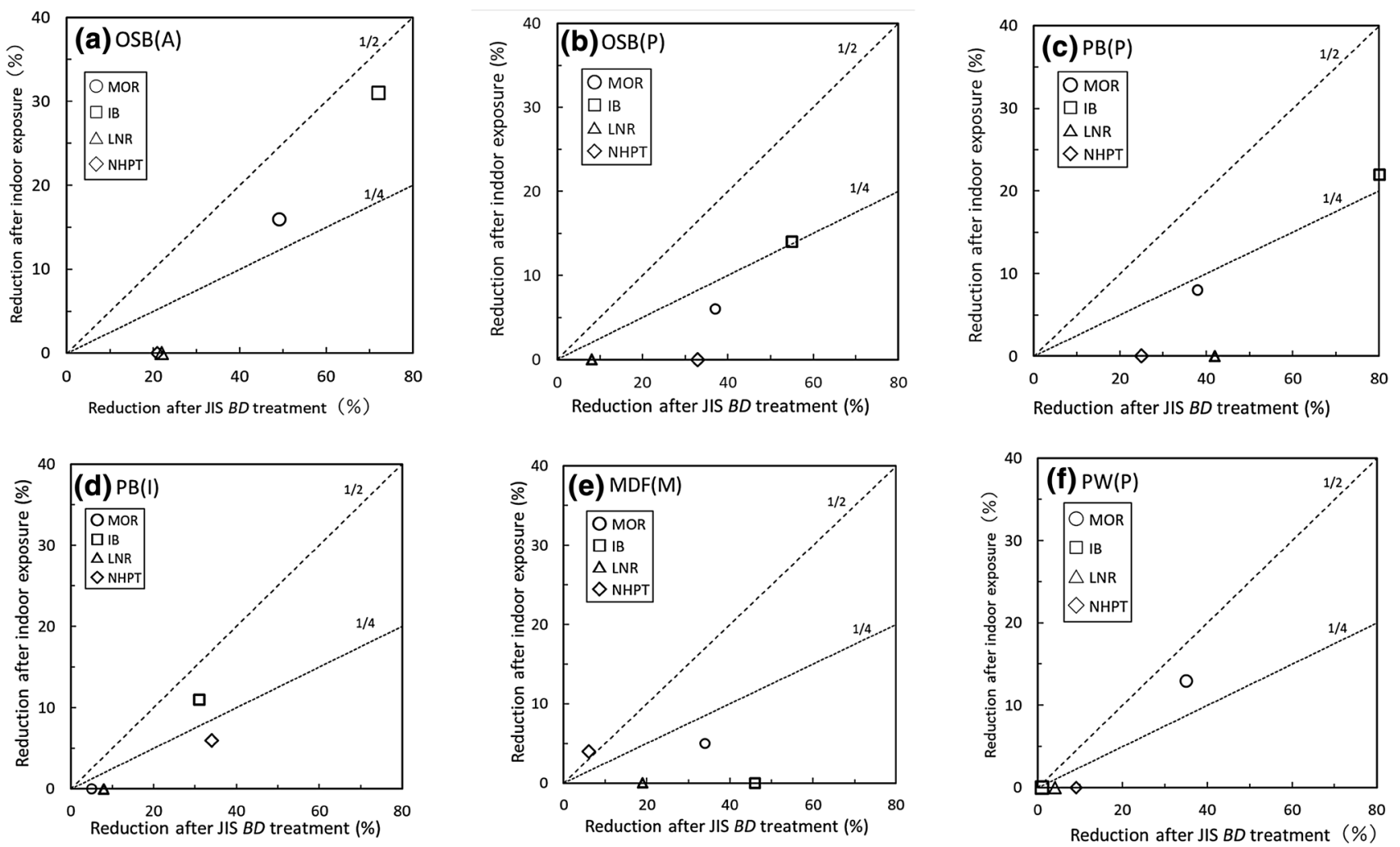

Fig. 2 Comparison of strength reduction between the indoor exposure and accelerated aging tests. JIS BD; 2-h boiling followed by reconditioning (oven-drying for $24 \mathrm{~h}$ at $60{ }^{\circ} \mathrm{C}$, followed by 2 weeks of conditioning at $20^{\circ} \mathrm{C}$ and $60 \% \mathrm{RH}$ )

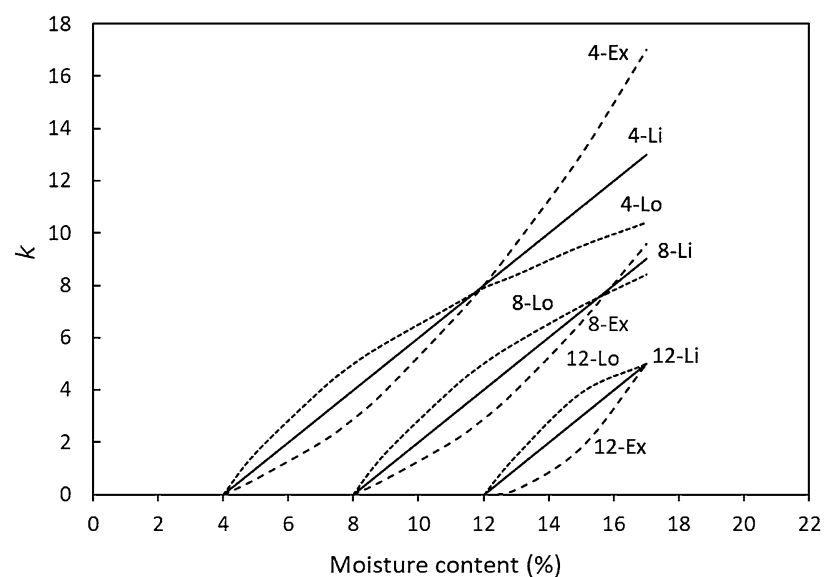

Fig. 3 Setting up a coefficient of deterioration $(k)$. Symbol "4-Li", for example, indicates that $k=0$ at a $4 \%$ moisture content and $k$ increases linearly. Likewise, Ex and Lo indicate exponential and logarithmic increase, respectively

the reduction in the cohesion of the glue line (plywood) or bonding points (mat-formed panels) [20,30]. Although the hydrolysis of resin binders causes a reduction in the adhesive cohesion itself and is considered to be one of the deterioration factors, the binders of sample panels used in this research (see Table 1) are difficult to hydrolyze. Therefore, it is natural to think that the reduction in cohesion happens at the interface between the wood element and resin binder, and that the reduction is caused by the repetition of swelling/ shrinking stresses owing to changes in the moisture content. However, it is not easy to predict the size of swelling/shrinking stresses since they involve relaxation matters dependent on the moisture content levels [31]. Therefore, this study introduced a simple concept of DI for which the value becomes greater with the increases of moisture content and duration. DI is defined by the following equation:

$\mathrm{DI}=\sum(k \times t)$,

where $k$ is the coefficient of deterioration dependent on the moisture content and $t$ is the period over which $k$ is maintained.

To find a calculation method for DI that correlates best with the observed reduction in mechanical properties, this study determined nine kinds of $k$ as a function of the moisture content (see Fig. 3). This concept is based on two types of ideas: one is in reference to the lower limit of moisture content $\left(\mathrm{MC}_{k}\right)$, for which $k$ equals to zero, and this was set at three levels of 4,8 , and $12 \%$. Note that the moisture content history below the lower limit does not affect the mechanical properties. The other involves a manner of weighing 
Table 6 Values of the coefficient of deterioration $(k)$ for each moisture content level

\begin{tabular}{llllllllll}
\hline $\mathrm{MC}_{k}(\%)$ & WM & Symbol & \multicolumn{7}{c}{ Moisture content level (\%) } \\
\cline { 3 - 9 } & & & $4-6$ & $6-8$ & $8-10$ & $10-12$ & $12-14$ & $14-16$ & $16-18$ \\
\hline 4 & Linear & $4-\mathrm{Li}$ & 1.0 & 3.0 & 5.0 & 7.0 & 9.0 & 11.0 & 13.0 \\
& Exponent & $4-\mathrm{Ex}$ & 0.5 & 2.1 & 4.1 & 6.6 & 9.6 & 13.1 & 17.1 \\
& Logarithm & $4-\mathrm{Lo}$ & 1.6 & 4.0 & 5.8 & 7.2 & 8.4 & 9.5 & 10.4 \\
8 & Linear & $8-\mathrm{Li}$ & - & - & 1.0 & 3.0 & 5.0 & 7.0 & 9.0 \\
& Exponent & $8-\mathrm{Ex}$ & - & - & 0.6 & 2.1 & 4.1 & 6.6 & 9.6 \\
\multirow{3}{*}{12} & Logarithm & 8-Lo & - & - & 1.6 & 4.0 & 5.8 & 7.2 & 8.4 \\
& Linear & $12-\mathrm{Li}$ & - & - & - & - & 1.0 & 3.0 & 5.0 \\
& Exponent & $12-\mathrm{Ex}$ & - & - & - & - & 0.2 & 1.8 & 5.0 \\
& Logarithm & 12-Lo & - & - & - & - & 1.5 & 3.9 & 5.0 \\
\hline
\end{tabular}

$M C_{k}$ lower limit of moisture content at which $k=0, W M$ a weighing manner of moisture content to $k$

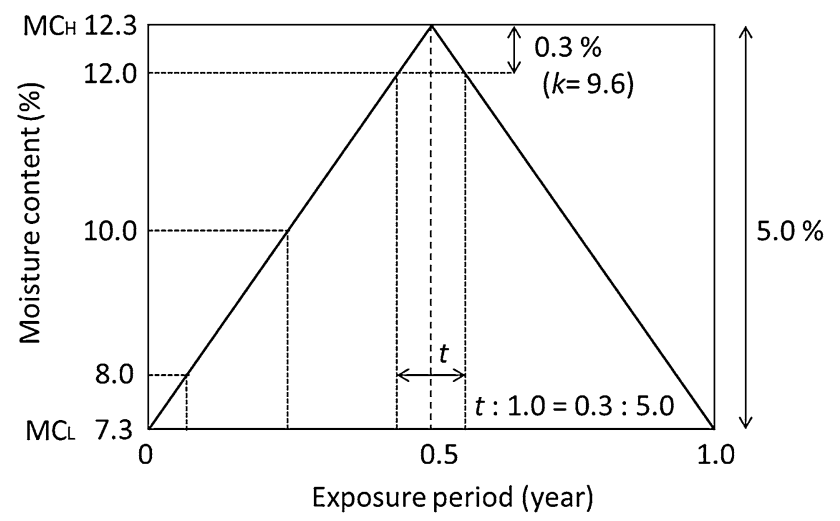

Fig. 4 Calculation method of $t$

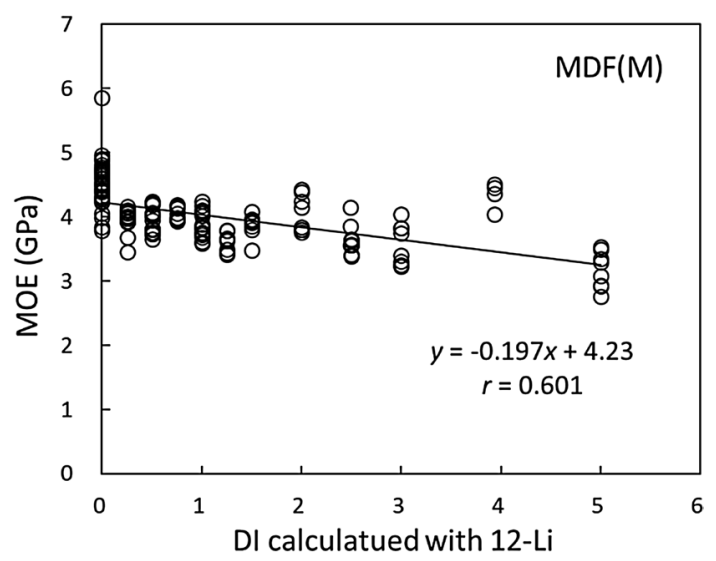

Fig. 5 Example of a correlation between DI and MOE for the $\mathrm{MDF}(\mathrm{M})$ panel. $r$ coefficient of correlation

moisture content in reference to $k$, and employs the use of linear, exponential, and logarithmic equations for each lower limit level. For the actual calculation process of DI, the step variation of $k$ for every $2 \%$ increment of moisture content was used, as shown in Table 6. Through the use of the moisture content history shown in Table 3 and the value of $k$ shown in Table 6 , the DI of each indoor exposure condition was calculated. To simplify the calculation, the following working hypothesis was formulated in reference to the moisture content history: the moisture content changed linearly between $\mathrm{MC}_{\mathrm{L}}$ and $\mathrm{MC}_{\mathrm{H}}$ over the cycle of year. Consequently, the value of $t$ was calculated proportionally to a portion of the moisture content history. For example, Fig. 4 shows the case of $\mathrm{PB}(\mathrm{P})$ exposed at 'Roof sheathing' $\left(\mathrm{MC}_{\mathrm{L}}\right.$; $7.3 \%, \mathrm{MC}_{\mathrm{H}} ; 12.3 \%$ ) for one year, and thus, the DI for 6 years of exposure was calculated as follows when the $k$ values were set at 4-Ex (lower limit; 4\%, weighing manner; exponent), as shown in Table 6:

$$
\begin{aligned}
\mathrm{DI}= & 6 \times\{9.6 \times 0.3 /(12.3-7.3)+6.6 \times 2.0 /(12.3-7.3) \\
& +4.1 \times 2.0 /(12.3-7.3)+2.1 \times 0.7 /(12.3-7.3)\}=30.9
\end{aligned}
$$

\section{Correlations between the DI and reduction in mechanical properties}

Figure 5 shows an example of the correlation between the DI and MOE for the MDF(M) panel; each plot indicates a MOE value for each test specimen. The calculation method for the DI in this example was 12-Li (lower limit; $12 \%$, weighing manner; linear), which showed the highest correlation among the nine determined $k$ values. All results from the correlation analysis are summarized in Table 7 as a correlation coefficient $(r)$ table. The $r$ values were all significant at a $1 \%$ level and the blank marks, '-', indicate that there was no significant correlation. The method showing the highest correlation among the nine is highlighted in italic bold. There was an intermediate correlativity between the bending properties (MOE, MOR) and DI when the DI was calculated with a $\mathrm{MC}_{k}$ of $12 \%$ (12-Li, 12-Ex, and 12-Lo) for many of the test panels, especially for the $\operatorname{MDF}(\mathrm{M})$ panel. On the other hand, a significant correlativity to IB was only found for the $\mathrm{PB}(\mathrm{I})$ panel and it occurred when the $\mathrm{MC}_{k}$ was set at 
Table 7 Coefficients of correlation $(r)$ between DI and the deterioration of mechanical properties

\begin{tabular}{|c|c|c|c|c|c|c|c|c|c|c|}
\hline \multirow{2}{*}{$\begin{array}{l}\text { Mechanical } \\
\text { properties }\end{array}$} & \multirow[t]{2}{*}{ Panels } & \multicolumn{9}{|c|}{ Calculation methods of DI } \\
\hline & & 4-Li & 4-Ex & 4-Lo & 8-Li & 8-Ex & 8-Lo & 12-Li & $12-\mathrm{Ex}$ & 12-Lo \\
\hline \multirow[t]{6}{*}{ MOE } & $\operatorname{OSB}(\mathrm{A})$ & - & - & - & - & - & - & 0.458 & 0.486 & 0.435 \\
\hline & $\mathrm{OSB}(\mathrm{P})$ & - & - & - & - & - & - & 0.261 & 0.221 & 0.286 \\
\hline & $\mathrm{PB}(\mathrm{P})$ & - & - & - & - & & & 0.301 & 0.250 & 0.327 \\
\hline & $\mathrm{PB}(\mathrm{I})$ & - & - & - & - & - & - & - & - & - \\
\hline & $\operatorname{MDF}(\mathrm{M})$ & - & - & - & 0.333 & 0.391 & 0.258 & 0.601 & 0.601 & 0.601 \\
\hline & $\mathrm{PW}(\mathrm{P})$ & - & - & - & - & - & - & 0.227 & 0.228 & 0.223 \\
\hline \multirow[t]{5}{*}{ MOR } & OSB(A) & - & - & - & - & 0.234 & - & 0.371 & 0.407 & 0.344 \\
\hline & $\mathrm{OSB}(\mathrm{P})$ & - & - & - & - & - & - & - & - & - \\
\hline & $\mathrm{PB}(\mathrm{P})$ & - & - & - & - & - & - & 0.289 & 0.251 & 0.309 \\
\hline & $\operatorname{MDF}(\mathrm{M})$ & - & - & - & - & 0.288 & - & 0.497 & 0.497 & 0.497 \\
\hline & $\mathrm{PW}(\mathrm{P})$ & - & - & - & - & - & - & - & - & - \\
\hline \multirow[t]{4}{*}{ IB } & OSB(A) & - & - & - & - & - & - & - & - & - \\
\hline & $\mathrm{OSB}(\mathrm{P})$ & - & - & - & - & - & - & - & - & - \\
\hline & $\mathrm{PB}(\mathrm{P})$ & - & - & - & - & - & - & - & - & - \\
\hline & $\mathrm{PB}(\mathrm{I})$ & 0.305 & 0.287 & 0.315 & 0.247 & 0.233 & 0.262 & - & - & - \\
\hline \multirow[t]{3}{*}{ NHPT } & $\mathrm{PB}(\mathrm{P})$ & - & - & - & - & - & - & - & - & - \\
\hline & $\mathrm{PB}(\mathrm{I})$ & - & - & - & - & - & - & - & - & - \\
\hline & $\operatorname{MDF}(\mathrm{M})$ & - & - & - & - & - & - & - & - & - \\
\hline
\end{tabular}

Bold italic values indicate the highest correlation

$D I$ deterioration intensity. $O S B, P B, M D F, P W$ see Table $1 . M O E, M O R, I B, N H P T$ see Table 2

'-' indicates no significant correlation
4 or $8 \%$. There was no significant correlation between NHPT and DI, no matter which method was applied.

In the analysis of the outdoor exposure test results, coordinate transformation from a linear scale of the WI to a logarithmic or square root scale of WI was found to improve the correlativity to the deterioration in the mechanical properties of the panels [16]. Therefore, this technique was used in this research. The results of the correlation analysis are summarized in Table 8 and the $r$ values shown here are all significant at a $1 \%$ level. The method showing the highest correlation is highlighted in bold. Comparing the $r$ values between Tables 7 and 8 for each calculation method, it was found that the coordinate transformation from a linear scale of DI to a logarithmic or square root scale of DI increased the correlativity in almost every case. Nevertheless, there was no significant correlation between NHPT and DI.

\section{Prediction of long-term performance}

Long-term mechanical durability was predicted by the use of regression equations obtained using the calculation method of DI that showed the highest $r$ value in Table 8. When more than one method produced the highest $r$ value, one was freely chosen. The prediction was conducted for the cases with $r$ values greater than 0.3 , and for the exposure condition of 'Cyclic humidity', in which a panel's moisture content fluctuates twice per year between $\mathrm{MC}_{\mathrm{L}}(7.5-9.0 \%)$ and $\mathrm{MC}_{\mathrm{H}}(13.3-16.2 \%)$, as shown in Table 3. These repeated humidity conditions are assumed to present the influence of dew condensation in a wall or accidental water troubles such as the leakage of rain.

Table 9 lists the regression equations used for the prediction, values of DI for 10-, 20-, and 30-year exposure to 'Cyclic humidity' conditions, and the predicted retentions (\%) of the mechanical properties. The results show that bending performance of the panels may reduce to $55-84 \%$ of the original value when they are subjected to such the moisture fluctuation over 10 years. This indicates the importance of early detection of water troubles which might occur in the roof, wall, or floor.

\section{Conclusions}

To investigate the long-term durability of wood-based panels, test results from six different indoor exposure experiments were integrated in this research. The answer for each objective of this research can be summarized as follows:

1. The six exposure conditions provided the test panels with the moisture content histories ranging from 5 to $18 \%$, and this range almost accounts for that of annual moisture content changes experienced when the panels are used as sheathing materials in residential construc- 


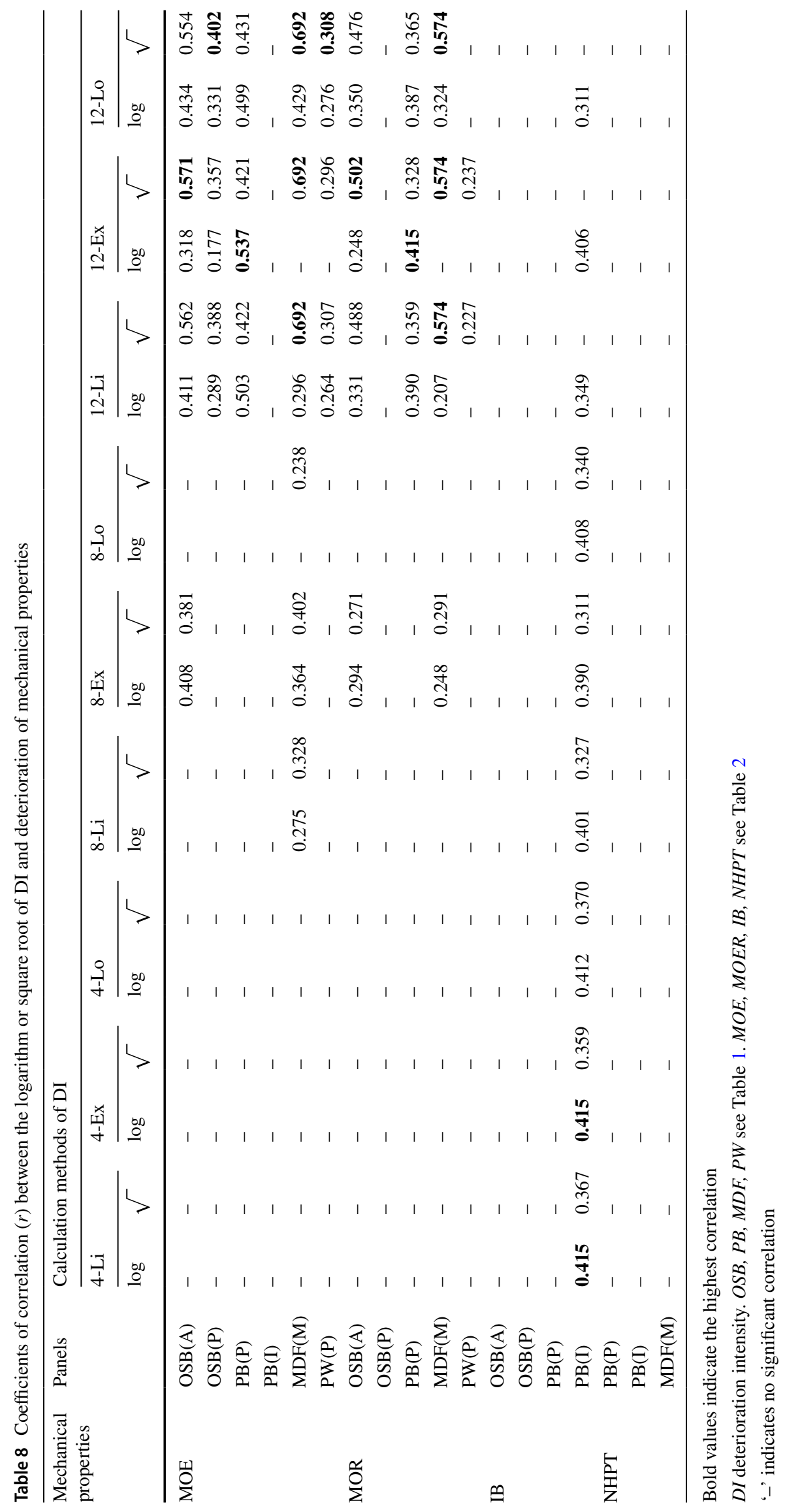


Table 9 Prediction of long-term mechanical durability of the panels subjected to the "cyclic humidity" exposure

\begin{tabular}{|c|c|c|c|c|c|c|c|c|c|c|c|c|}
\hline \multirow{2}{*}{$\begin{array}{l}\text { Mechanical } \\
\text { properties }\end{array}$} & \multirow[t]{2}{*}{ Panels } & \multicolumn{2}{|c|}{$Y=-a X+b$} & \multicolumn{3}{|c|}{$Y$ : retention $(\%)$} & \multicolumn{3}{|c|}{ Values of DI } & \multicolumn{3}{|c|}{ Predicted values of $Y(\%)$} \\
\hline & & Symbol & $X$-axis & $r$ & $a$ & $b$ & 10-year & 20-year & 30-year & 10-year & 20-year & 30-year \\
\hline \multirow[t]{5}{*}{ MOE } & $\mathrm{OSB}(\mathrm{A})$ & 12-Ex & $\sqrt{\mathrm{DI}}$ & 0.571 & 6.99 & 89.8 & 25.0 & 50.0 & 75.0 & 55 & 40 & 29 \\
\hline & $\mathrm{OSB}(\mathrm{P})$ & 12-Lo & $\sqrt{\mathrm{DI}}$ & 0.402 & 3.98 & 96.2 & 19.5 & 39.0 & 58.5 & 79 & 71 & 66 \\
\hline & $\mathrm{PB}(\mathrm{P})$ & 12-Ex & $\log \mathrm{DI}$ & 0.537 & 10.9 & 89.6 & 9.0 & 18.0 & 27.0 & 79 & 76 & 74 \\
\hline & $\operatorname{MDF}(\mathrm{M})$ & $12-\mathrm{Li}$ & $\sqrt{\mathrm{DI}}$ & 0.692 & 10.9 & 103.9 & 5.0 & 10.0 & 15.0 & 79 & 69 & 62 \\
\hline & $\mathrm{PW}(\mathrm{P})$ & 12-Lo & $\sqrt{\mathrm{DI}}$ & 0.308 & 3.59 & 99.7 & 25.0 & 50.0 & 75.0 & 82 & 74 & 69 \\
\hline \multirow[t]{3}{*}{ MOR } & $\mathrm{OSB}(\mathrm{A})$ & 12-Ex & $\sqrt{\mathrm{DI}}$ & 0.502 & 6.88 & 96.0 & 25.0 & 50.0 & 75.0 & 62 & 47 & 36 \\
\hline & $\mathrm{PB}(\mathrm{P})$ & 12-Ex & $\log$ DI & 0.415 & 9.08 & 92.2 & 9.0 & 18.0 & 27.0 & 84 & 81 & 79 \\
\hline & $\operatorname{MDF}(\mathrm{M})$ & $12-\mathrm{Li}$ & $\sqrt{\mathrm{DI}}$ & 0.574 & 7.89 & 101.5 & 5.0 & 10.0 & 15.0 & 84 & 77 & 71 \\
\hline IB & $\mathrm{PB}(\mathrm{I})$ & 4-Li & $\log$ DI & 0.415 & 12.0 & 105.1 & 70 & 140 & 210 & 83 & 79 & 77 \\
\hline
\end{tabular}

$D I$ deterioration intensity. $O S B, P B, M D F, P W$ see Table $1 . M O E, M O R, I B$ see Table 2

Symbol see Table $6, r$ coefficient of correlation

tion in Japan. Data from all exposures up to a maximum of 10 years were integrated and it was found that the reduction percentage in the mean value of the mechanical property was dependent on the panel type and mechanical property. It was in the range of $0-16 \%$ for the MOR, $3-22 \%$ for the MOE, $11-31 \%$ for the IB, and $0-8 \%$ for the NHPT. No reduction was recognized for the LNR.

2. The reduction percentages cited above were compared with those obtained after an accelerated aging test (JIS BD; 2-h boiling and drying). The results showed that strength reductions caused by the indoor exposure tests up to a maximum of 10 years were less than half of those caused by JIS BD, and less than a quarter for the properties of MOR, LNR, and NHPT.

3. Various calculation methods for the deterioration intensity (DI) based on the moisture content history were investigated to develop a standardized method for predicting the long-term durability of wood-based panels. The results showed that a DI calculated with moisture content history of more than $12 \%$ increased the correlativity between DI and reduction in a mechanical property, and that the coordinate transformation from a linear scale of DI to a logarithmic or square root scale of DI also increased its correlativity.

Acknowledgements The indoor exposure tests presented in this paper were conducted as part of a project organized by the Research Working Group on Wood-based Panels from the Japan Wood Research Society. The authors express their thanks to all participants in this project. This study was supported by a Grant-in-Aid for Scientific Research (21380108) from the Ministry of Education, Culture, Sports, Science and Technology of Japan and by a grant-in-aid from Ematyu-fundation in 2013. The authors are grateful for the grant received.

\section{References}

1. JIS A 5905 (2014) JIS standard for fiberboard. Japanese Standards Association, Tokyo

2. JIS A5908 (2015) JIS standard for particleboard. Japanese Standards Association, Tokyo

3. McNatt JD, Link CL (1989) Analysis of ASTM D1037 accelerated aging test. For Prod J 39:51-57

4. Kajita H, Mukudai J, Yano H (1991) Durability evaluation of particleboards by accelerated aging tests. Wood Sci Technol 25:239-249

5. ASTM-D 1037 (1993) Standard test method for properties of woodbased fiber and particle panel materials. American Society for Testing and Materials (ASTM), West Conshohocken

6. APA PRP 108 (1994) Performance standards and qualification policy for structural-use panels. APA-The Engineering Wood Association, Tacoma

7. EN321 (1993) Fiberboards, cyclic tests in humid conditions. European Standard

8. Carroll MM, Bergin EG, Fiehl AO (1969) Accelerated and 5-year exposure tests on exterior type plywood. For Prod J 19:43-51

9. Lehmann WF (1977) Durability of composition board products. Proc WSU Symp Particleboard 11:351-368

10. Lehmann WF (1978) Cyclic moisture conditions and their effect on strength and stability of structural flakeboards. For Prod J 28:23-31

11. Inoue A (1992) A new method for predicting bond durability. I. Outdoor exposure test of plywood subjected to accelerated aging treatment (in Japanese). Mokuzai Gakkaishi 38:923-930

12. River BH (1994) Outdoor aging of wood-based panels and correlation with laboratory aging. For Prod J 44:55-65

13. Okkonen EA, River BH (1996) Outdoor aging of wood-based panels and correlation with laboratory aging. Part 2 . For Prod J 46:68-74

14. Suzuki S, Watai J (2000) Literature review for durability performance of wood and wood-based material (in Japanese). Bull Shizuoka Univ For 24:63-70

15. Sekino N, Suzuki S (2002) Durability of wood-based panels subjected to ten-year outdoor exposure in Japan. In: Proceedings of the 6th pacific rim bio-based composites symposium, Portland, USA, vol 1 pp 323-332

16. Sekino N, Sato H, Adachi K (2014) Evaluation of particleboard deterioration under outdoor exposure using several different types of weathering intensity. J Wood Sci 60:141-151 
17. Kojima Y, Shimada T, Suzuki S (2011) Evaluation of the weathering intensity of wood-based panels under outdoor exposure. J Wood Sci 57:408-414

18. Kojima Y, Shimada T, Suzuki S (2012) Modified method for evaluating weathering intensity using outdoor exposure tests on woodbased panels. J Wood Sci 58:525-531

19. Korai H, Fujimoto Y (2015) Nail-head pull-through strength and lateral nail resistance strength of wood-based boards subjected to various climatic conditions in Japan. J Wood Sci 61:401-411

20. Wu Q, Lee JN (2002) Thickness swelling of oriented strandboard under long-term cyclic humidity exposure condition. Wood Fiber Sci 34:125-139

21. Korai H, Kojima Y, Suzuki S (2015) Bending strength and internal bond strength of wood-based boards subjected to various exposure conditions. J Wood Sci 61:500-509

22. Sekino N, Sasaki Y (2015) Deterioration of nail-joint performance of several wood-based panels used for roof sheathing (in Japanese). Bull Iwate Univ For 46:37-57

23. JAS (2003) JAS standard specification for construction panel. JPICEW, Tokyo

24. JAS (2003) JAS standard specification for plywood. JPIC-EW, Tokyo

25. ASTM D1037-96a (1996) Standard methods of evaluating the properties of wood-base fiber and particle panel materials. 20. American Society for Testing and Materials, West Conshohocken
26. Sekino N, Suematsu M, Korai H, Yasui E (1999) Measurements of sorption isotherms of selected commercial wood-based panels and prediction of moisture content changes in service (in Japanese). Mokuzai Gakkaishi 45:237-243

27. Sekino N, Korai H, Suzuki S (2005) How durable are wood-based panel products?- toward the establishment of durability estimation methods. In: Proceedings of the ninth European panel products symposium, pp 269-274

28. Kojima Y, Suzuki S (2011) Evaluating the durability of wood-based panels using internal bond strength results from accelerated aging treatments. J Wood Sci 57(1):7-13

29. Kojima Y, Suzuki S (2011) Evaluation of wood-based panel durability using bending properties after accelerated aging treatments. J Wood Sci 57(2):126-133

30. Sekino N, Inoue M (1996) Techniques required for producing dimensionally stable wood-based panels-mechanisms and method to reduce thickness swelling (in Japanese). Wood Ind 51(5):194-197

31. Sekino N, Sasaki T (2004) Poisson's ratio of wood-based panels and Poisson's effect of hygroscopic linear expansion under a uniaxially dimensional restraint (in Japanese). J Mater Sci Jpn 53(4):396-401 